\title{
The usefulness of pleural fluid presepsin, C-reactive protein, and procalcitonin in distinguishing different causes of pleural effusions
}

\author{
Naoki Watanabe ${ }^{1 *} \mathbb{D}$, Tomoya Ishii ${ }^{1}$, Nobuyuki Kita', Nobuhiro Kanaji ${ }^{1}$, Hiroyuki Nakamura ${ }^{2}$, Nobuki Nanki ${ }^{3}$,
} Yutaka Ueda ${ }^{4}$, Yasunori Tojo ${ }^{5}$, Norimitsu Kadowaki ${ }^{1}$ and Shuji Bandoh ${ }^{1}$

\begin{abstract}
Background: We aimed to determine the presepsin concentration in pleural fluid from patients with pleural effusions of different aetiologies and to compare its diagnostic value with that of pleural fluid C-reactive protein (CRP) and procalcitonin (PCT).

Methods: We enrolled 132 patients with pleural effusion who underwent diagnostic evaluation, and we classified them into six categories: empyema, parapneumonic effusion, tuberculous effusion, malignant effusion, paramalignant effusion, and transudate effusion. Additionally, all pleural effusions were categorised as infectious or non-infectious effusions.

Results: Receiver operating characteristic analysis was used to evaluate diagnostic performance. When diagnosing empyema, the marker with the highest sensitivity was pleural fluid presepsin (cut-off: 754 pg/mL; sensitivity: 90.9\%, specificity: 74.4\%) and that with the highest specificity was pleural fluid CRP (cut-off: $4.91 \mathrm{mg} / \mathrm{dL}$; sensitivity: 63.6\%, specificity: 89.3\%). Pleural fluid PCT tended to be lower in patients with empyema than in those with parapneumonic effusion, but this was not useful for the diagnosis of empyema. When diagnosing infectious pleural effusion, a combination of pleural fluid CRP (cut-off: $2.59 \mathrm{mg} / \mathrm{dL}$ ) and presepsin (cut-off: $680 \mathrm{pg} / \mathrm{mL}$ ) produced the highest diagnostic accuracy (83.3\%).

Conclusions: Pleural fluid presepsin was found at high levels in patients with empyema and parapneumonic effusion. This pattern closely resembles the previously reported pattern of pleural fluid CRP. Some combinations of pleural fluid inflammatory markers may be more clinically useful than these markers in isolation.
\end{abstract}

Keywords: Presepsin, C-reactive protein, Procalcitonin, Empyema, Pleural effusion

\section{Background}

To investigate the aetiology of pleural effusion, a variety of examinations are typically performed, including pleural fluid cell and differential white blood cell counts, cytological examination, and bacterial culture following Light's criteria [1]. However, the information obtained by these methods is limited, and delays in the diagnosis and

\footnotetext{
* Correspondence: naoki-w@med.kagawa-u.ac.jp

'Department of Internal Medicine, Hematology, Rheumatology and

Respiratory Medicine, Faculty of Medicine, Kagawa University, 1750-1

Ikenobe, Miki-cho, Kita-gun, Kagawa 761-0793, Japan

Full list of author information is available at the end of the article
}

the initiation of appropriate therapy for infectious effusions can increase the rate of complications. Therefore, rapid diagnosis and determination of whether the cause of pleural effusion is infection are beneficial in the treatment of this condition.

Although clinical microbiology testing can confirm the presence of infection, a positive culture is observed in only about $60 \%$ of parapneumonic effusions, and the time required to obtain a positive culture can be prolonged [2]. Various pleural biomarkers have therefore been investigated as methods for differentiating infectious pleural effusion [3-5].

(c) The Author(s). 2018 Open Access This article is distributed under the terms of the Creative Commons Attribution 4.0 International License (http://creativecommons.org/licenses/by/4.0/), which permits unrestricted use, distribution, and reproduction in any medium, provided you give appropriate credit to the original author(s) and the source, provide a link to the Creative Commons license, and indicate if changes were made. The Creative Commons Public Domain Dedication waiver (http://creativecommons.org/publicdomain/zero/1.0/) applies to the data made available in this article, unless otherwise stated. 
Presepsin, also known as soluble CD14 subtype, is a protein reported to be increased specifically in the blood of patients with sepsis [6] and is therefore used to predict sepsis in patients in emergency or intensive care units [7]. Following stimulation by pathogens, presepsin is released via shedding from the surface of various types of immune cells, including macrophages, monocytes, and neutrophils, which are implicated in phagocytosis and the cleavage of membrane CD14 by lysosomal enzymes from granulocytes in response to bacterial infection [8]. Several studies have confirmed that presepsin is a more specific and sensitive marker for the diagnosis of sepsis compared with C-reactive protein (CRP), interleukin-6 (IL-6), or procalcitonin (PCT) [7], [9-11]. However, few studies have investigated the diagnostic value of presepsin levels in body fluids.

The aim of the present study was to evaluate the pleural fluid concentrations of presepsin, CRP, and PCT in patients with pleural effusions of various causes and to explore the usefulness of these markers in predicting an infectious aetiology.

\section{Methods}

\section{Study design}

In this cross-sectional study, we set the target number of cases based on feasibility. An average of 30 thoracentesis procedures are performed at the participating institutions annually. Allowing for ineligible patients and a consent rate of $90 \%$, the target number of cases was set at 135 . This study protocol was approved by the institutional review boards of Kagawa University Hospital and all other participating institutions. All patients provided written informed consent prior to participation.

Between November 2015 and March 2017, 145 patients aged $\geq 18$ years with pleural effusion and planned thoracentesis for diagnosis were initially enrolled in the study. Among these, seven patients with chronic maintenance dialysis or continuous hemodiafiltration and six patients with severe renal failure (GFR of $<15 \mathrm{~mL} / \mathrm{min} /$ $1.73 \mathrm{~m}^{2}$ ) were excluded from further participation.

\section{Diagnostic criteria}

Pleural fluid samples were collected from 132 patients. Each diagnosis was made according to the diagnostic criteria described below. The cases were also categorised as infectious or non-infectious effusions.

We classified the aetiology of pleural effusion into seven categories. 1) Empyema was defined as a grossly purulent pleural effusion accompanied by bacteria detected by Gram staining or a positive culture for bacteria. 2) Parapneumonic effusion was defined as pleural effusion associated with bacterial pneumonia. 3) Tuberculous pleural effusion was based on the presence of a caseous granuloma in the pleural biopsy and/or a positive culture for
Mycobacterium tuberculosis in the pleural fluid or biopsy material or a positive sputum culture with an exudative pleural effusion and both a clinical and radiological response to anti-tuberculous treatment. 4) Malignant effusion was diagnosed when malignant cells were found in the pleural fluid or in a biopsy specimen. 5) Paramalignant effusion was diagnosed in patients with a known malignancy or subsequent diagnosis of malignancy but with negative cytology and no obvious alternative diagnosis. 6) Transudate effusion was diagnosed by the attending physician based on Light's criteria as well as the general condition of the patient. 7) Any pleural effusion not meeting one of the above diagnostic criteria was categorised as an unclassifiable pleural effusion.

Notably, the cases of unclassifiable pleural effusion were divided into infectious or non-infectious effusions, based on the judgment of the attending physician and the reactivity of the condition to antimicrobial drugs. Therefore, the infectious pleural effusion cases in this study included all the patients with empyema, parapneumonic effusion, and tuberculous pleural effusion as well as those with unclassifiable pleural effusion who were clinically diagnosed as having infectious pleural effusion.

\section{Procedures}

Thoracentesis was performed under local anaesthesia. Samples of pleural fluid were immediately subjected to routine examinations for analysis (e.g. $\mathrm{pH}$, total protein, glucose, and lactate dehydrogenase), total and differential cell counts, and cytological and microbiological examination. Pleural fluid was collected in a serum-separating tube for CRP measurement and in a tube containing EDTA for presepsin and PCT measurement. Samples were centrifuged at $1200 \times g$ for $5 \mathrm{~min}$ at $4{ }^{\circ} \mathrm{C}$, and the resulting supernatants were stored at $-30^{\circ} \mathrm{C}$ until they were assayed. Simultaneously, venous blood was obtained and analysed for white blood cell count and for lactate dehydrogenase, total protein, blood urea nitrogen, creatinine, and CRP content in addition to any other appropriate assessments ordered by the attending physician. Aliquots of blood plasma were stored at $-30^{\circ} \mathrm{C}$ prior to the assessment of presepsin and PCT levels.

\section{Biomarker assays}

Assays for the three inflammatory markers, presepsin, CRP, and PCT, were performed on the cell-free supernatants of pleural fluid and blood plasma samples. All samples were tested in random order by technicians blinded to the clinical diagnosis.

Pleural fluid CRP measurement was performed by a latex-enhanced immunoturbidimetric assay at an external clinical laboratory testing facility (SRL Inc., Tokyo, Japan). PCT concentrations in pleural fluid and blood plasma were measured using the Wako i30 micro-total 
analysis system ( $\mu$ TAS) and Wako-BRAHMS PCT assay (Wako Pure Chemical Industries, Ltd., Osaka, Japan), respectively. Presepsin concentrations in pleural fluid and blood plasma were determined using a compact automated immunoanalyser based on a chemiluminescent enzyme immunoassay (PATHFAST; Mitsubishi Chemical Medience Corporation, Tokyo, Japan).

\section{Statistical analysis}

Data are presented as means \pm standard deviation (SD) for data with a normal distribution and as medians with interquartile ranges in parentheses for skewed data. Normality of distribution was ascertained using the Shapiro-Wilk test. For comparing categorical data, a chi-squared test was performed. For the evaluation of diagnostic performance, receiver operating characteristic (ROC) analysis was performed, ROC curves were generated by plotting sensitivity against 1 -specificity, and the area under the curve (AUC) with 95\% confidence intervals (CI) was calculated. The Youden index was used to identify the cut-off values with potential diagnostic significance. All statistical analyses were performed using JMP software version 12.2.0 (SAS institute Inc., Cary, $\mathrm{NC}$, USA), and $p$-values of $<0.05$ were considered statistically significant.

\section{Results}

\section{General characteristics of pleural effusions}

Of the 132 patients classified as having pleural effusions, $122(92.4 \%)$ were diagnosed with exudative effusion and $10(7.6 \%)$ were diagnosed with transudate effusion. Additionally, 38 (28.8\%) patients were diagnosed with infectious pleural effusions, while $94(71.2 \%)$ were diagnosed with non-infectious pleural effusions.

The exudative effusion group was further divided into the following six subgroups according to the diagnosis: empyema, 11 (9.0\%); parapneumonic effusion, 16 (13.1\%); tuberculous pleural effusion, 9 (7.4\%); malignant effusion, 46 (37.7\%); paramalignant effusion, 13 (10.7\%); and unclassified effusion, 27 (22.1\%). Although the attending physician investigated thoroughly to determine the cause of pleural effusion, the cause remained unknown in 17 cases. Among the other 10 cases of unclassified effusion, there were 2 cases associated with pneumothorax, 2 cases of chronic empyema, 1 case associated with collagen disease, 1 case associated with trauma, 1 case associated with interstitial pneumonia, 1 case associated with asbestos, 1 case of chylous pleural effusion, and 1 case of reactive pleural effusion due to Clonorchis sinensis. The chronic empyema cases categorised as unclassified effusions did not meet the diagnostic criteria of empyema for this study. Of the 27 unclassifiable pleural effusion cases, only the two chronic empyema cases were judged as being infectious pleural effusion. The demographic data and the pleural fluid characteristics of the 132 patients included in the present study are shown in Table 1.

\section{Pleural fluid levels of presepsin, CRP, and PCT Presepsin measurements}

Pleural fluid presepsin levels were significantly higher in patients with empyema or parapneumonic effusion compared with patients who had other types of effusions. However, no difference in the pleural fluid presepsin level was observed between these two types of effusions (Table 2, Fig. 1a). Presepsin levels were significantly higher in pleural fluid than in blood for all types of effusions.

The diagnostic performance of pleural fluid presepsin values as determined from a ROC analysis is presented in Table 3. Pleural fluid presepsin may represent a useful marker for the differentiation of empyema from other types of effusions. Using a cut-off point of $754 \mathrm{pg} / \mathrm{mL}$, pleural presepsin presented $90.9 \%$ sensitivity and $74.4 \%$ specificity for the diagnosis of empyema.

A similar cut-off point was observed in another pair comparison. In distinguishing parapneumonic effusion from other types of effusions (excluding empyema) with a cut-off point of $680 \mathrm{pg} / \mathrm{mL}$, the sensitivity was $81.3 \%$ and the specificity was $74.3 \%$.

\section{CRP measurements}

Pleural fluid CRP levels were significantly higher in patients with empyema, parapneumonic effusion, and tuberculous effusion compared with patients who had malignant or transudate effusions. There was no difference in pleural fluid CRP levels between empyema and parapneumonic effusion cases. Additionally, no difference in pleural fluid CRP levels was observed between malignant effusion, paramalignant effusion, and transudate effusion cases. CRP levels were significantly lower in pleural fluid than in blood for all types of effusions (Table 2, Fig. 1b).

The CRP diagnostic performance based on a ROC analysis of pleural fluid CRP values is presented in Table 4. Pleural fluid CRP was found to represent a useful marker for the diagnosis of empyema; using a cut-off point of $4.91 \mathrm{mg} / \mathrm{dL}$, pleural fluid CRP presented $63.6 \%$ sensitivity and $89.3 \%$ specificity for the diagnosis of empyema. In distinguishing between infectious effusions and non-infectious effusions, the sensitivity was $65.8 \%$ and the specificity was $90.4 \%$ when using a pleural fluid CRP cut-off point of $2.59 \mathrm{mg} / \mathrm{dL}$. Pleural fluid CRP showed the highest accuracy compared with pleural fluid presepsin and PCT.

\section{PCT measurements}

Pleural fluid PCT levels were significantly higher in patients with parapneumonic effusion compared with patients who had tuberculous effusion, malignant effusion, paramalignant effusion, or transudate effusion. No difference in pleural 
Table 1 Demographic data and pleural fluid characteristics $(n=132)$

\begin{tabular}{|c|c|c|c|c|c|c|c|}
\hline & $\begin{array}{l}\text { Empyema } \\
(n=11)\end{array}$ & $\begin{array}{l}\text { Parapneumonic } \\
(n=16)\end{array}$ & $\begin{array}{l}\text { Tuberculous } \\
(n=9)\end{array}$ & $\begin{array}{l}\text { Malignant } \\
(n=46)\end{array}$ & $\begin{array}{l}\text { Paramalignant } \\
(\mathrm{n}=13)\end{array}$ & $\begin{array}{l}\text { Transudates } \\
(n=10)\end{array}$ & $\begin{array}{l}\text { Unclassified } \\
(n=27)\end{array}$ \\
\hline Age (years) & $74.3 \pm 11.1$ & $76.7 \pm 10.1$ & $76.1 \pm 17.4$ & $74.5(67,82.3)$ & $77.2 \pm 10.9$ & $80.7 \pm 9.5$ & $79(73,88)$ \\
\hline Sex (male/female) & $9 / 2$ & $13 / 3$ & $4 / 5$ & $25 / 21$ & $9 / 4$ & $9 / 1$ & $20 / 7$ \\
\hline Pleural fluid white blood cell count & $\begin{array}{l}6355 \\
(2160,23,693)\end{array}$ & $\begin{array}{l}1870 \\
(963,6338)\end{array}$ & $\begin{array}{l}931 \\
(782,1325)\end{array}$ & $\begin{array}{l}1290 \\
(890,2355)\end{array}$ & $1532 \pm 999$ & $658 \pm 356$ & $\begin{array}{l}1045 \\
(613,4029)\end{array}$ \\
\hline Pleural fluid lymphocytes (\%) & $22.3 \pm 22.4$ & $33.3 \pm 26.5$ & $81.1 \pm 11.3$ & $36.5(17.3,63.5)$ & $57.3 \pm 28.9$ & $54.9 \pm 16.1$ & $73(35.5,86.5)$ \\
\hline Pleural fluid neutrophils (\%) & $67.7 \pm 31.1$ & $45.5(8.9,77.1)$ & $5.2 \pm 5.2$ & $5.0(1.4,20)$ & $10.0(4.5,16.5)$ & $16.1 \pm 16.1$ & $8.0(1.1,15)$ \\
\hline Pleural fluid glucose (mg/dL) & $10(1,107)$ & $160 \pm 62$ & $104 \pm 28$ & $106(74,123)$ & $104 \pm 33$ & $\begin{array}{l}117 \\
(110,141)\end{array}$ & $93 \pm 43$ \\
\hline Total protein in pleural fluid $(\mathrm{g} / \mathrm{L})$ & $3.8 \pm 1.1$ & $3.9 \pm 0.6$ & $4.2 \pm 0.9$ & $4.6(3.8,5.1)$ & $3.9(3.5,4.8)$ & $2.7 \pm 1.0$ & $4.5 \pm 1.1$ \\
\hline Total protein in serum $(\mathrm{g} / \mathrm{L})$ & $6.0 \pm 1.1$ & $6.3(5.8,6.6)$ & $6.5 \pm 0.6$ & $6.8 \pm 0.7$ & $6.9 \pm 0.7$ & $6.0(5.3,6.4)$ & $7.1 \pm 1.2$ \\
\hline $\begin{array}{l}\text { Total protein in pleural fluid/ } \\
\text { serum ratio }\end{array}$ & $0.65 \pm 0.19$ & $0.67(0.54,0.71)$ & $0.64 \pm 0.11$ & $0.67(0.58,0.72)$ & $0.62 \pm 0.10$ & $0.44 \pm 0.14$ & $0.63 \pm 0.14$ \\
\hline Pleural fluid LDH (U/L) & $1076(474,2522)$ & $496 \pm 247$ & $396 \pm 250$ & $410(267,775)$ & $234(164,392)$ & $\begin{array}{l}117(94 \\
128)\end{array}$ & $232(171,543)$ \\
\hline Serum LDH (U/L) & $189 \pm 71$ & $254(194,325)$ & $\begin{array}{l}205 \\
(186,245)\end{array}$ & $269(237,395)$ & $240 \pm 68$ & $\begin{array}{l}250 \\
(209,363)\end{array}$ & $191(152,238)$ \\
\hline LDH pleural fluid/serum ratio & $6.22(1.41,29.67)$ & $1.45(0.90,3.41)$ & $1.77 \pm 1.02$ & $1.25(0.97,2.92)$ & $0.88(0.76,1.77)$ & $0.42 \pm 0.17$ & $1.24(0.85,2.45)$ \\
\hline
\end{tabular}

$\mathrm{LDH}$, lactate dehydrogenase; Data are presented as the mean \pm SD for normally distributed data or as the median (interquartile ranges) for skewed data

fluid PCT levels was observed between empyema and parapneumonic effusion cases. Interestingly, pleural fluid PCT levels tended to be lower in empyema cases than in parapneumonic effusion cases. Pleural fluid PCT levels did not differ from blood PCT levels, except in patients with empyema (Table 2, Fig. 1c).

The PCT diagnostic performance based on a ROC analysis of pleural fluid PCT values is presented in Table 5 . This analysis revealed that pleural fluid PCT is unsuitable as a marker for the differentiation of empyema because its AUC was $<0.5$. However, pleural fluid PCT may be a useful marker in differentiating parapneumonic effusion from other type of effusions (excluding empyema); when using a cut-off point of $0.11 \mathrm{ng} / \mathrm{mL}$, the sensitivity was $75.0 \%$ and the specificity was $79.0 \%$.

The diagnostic accuracy of different marker combinations The diagnostic accuracy of combined cut-off values for the three inflammatory markers obtained in each ROC analysis is shown in Table 6. To distinguish between empyema and other type of effusions, a pleural fluid presepsin level of $>754 \mathrm{pg} / \mathrm{mL}$ and a pleural fluid CRP level of $>4.91 \mathrm{mg} / \mathrm{dL}$ yielded the highest accuracy rate (90.9\%). Similarly, when distinguishing between infectious pleural

Table 2 Levels of presepsin, CRP, and PCT in the pleural fluid and blood ( $n=105)$

\begin{tabular}{|c|c|c|c|c|c|c|}
\hline & Empyema $(n=11)$ & Parapneumonic $(n=16)$ & Tuberculous $(n=9)$ & Malignant $(n=46)$ & Paramalignant $(n=13)$ & Transudates $(n=10)$ \\
\hline \multicolumn{7}{|c|}{ Presepsin $(\mathrm{pg} / \mathrm{mL})$} \\
\hline PF & $1496 \pm 971$ & $854(682,1423)$ & $548 \pm 188$ & $463(347,609)$ & $438(319,812)$ & $531 \pm 172$ \\
\hline Blood & $776 \pm 362$ & $395(251,851)$ & $392 \pm 183$ & $258(162,318)$ & $259(200,322)$ & $402 \pm 144$ \\
\hline$p$-value & 0.0139 & 0.0330 & 0.0019 & $<0.0001$ & 0.0111 & 0.0125 \\
\hline \multicolumn{7}{|c|}{ CRP $(\mathrm{mg} / \mathrm{dL})$} \\
\hline PF & $5.57 \pm 4.40$ & $3.67(2.28,7.59)$ & $3.29 \pm 2.22$ & $0.55(0.21,1.48)$ & $0.90(0.53,2.46)$ & $0.41 \pm 0.43$ \\
\hline Blood & $19.11 \pm 9.88$ & $8.04(2.97,19.35)$ & $8.06 \pm 6.18$ & $1.62(0.49,5.80)$ & $3.12(1.37,10.66)$ & $1.00(0.25,2.18)$ \\
\hline$p$-value & 0.0001 & 0.0114 & 0.0047 & $<0.0001$ & 0.0069 & 0.0130 \\
\hline \multicolumn{7}{|c|}{ PCT $(\mathrm{ng} / \mathrm{mL})$} \\
\hline PF & $0.30(0.11,0.77)$ & $0.28(0.07,2.72)$ & $0.08 \pm 0.06$ & $0.05(0.03,0.10)$ & $0.10(0.04,0.50)$ & $0.12 \pm 0.08$ \\
\hline Blood & $1.43(0.25,3.26)$ & $0.30(0.13,2.13)$ & $0.08 \pm 0.05$ & $0.06(0.03,0.12)$ & $0.06(0.04,0.23)$ & $0.12 \pm 0.10$ \\
\hline$p$-value & 0.0272 & ns & ns & ns & ns & ns \\
\hline
\end{tabular}

Data are presented as the mean \pm SD for normally distributed data or median (interquartile ranges) for skewed data. PF: pleural fluid 

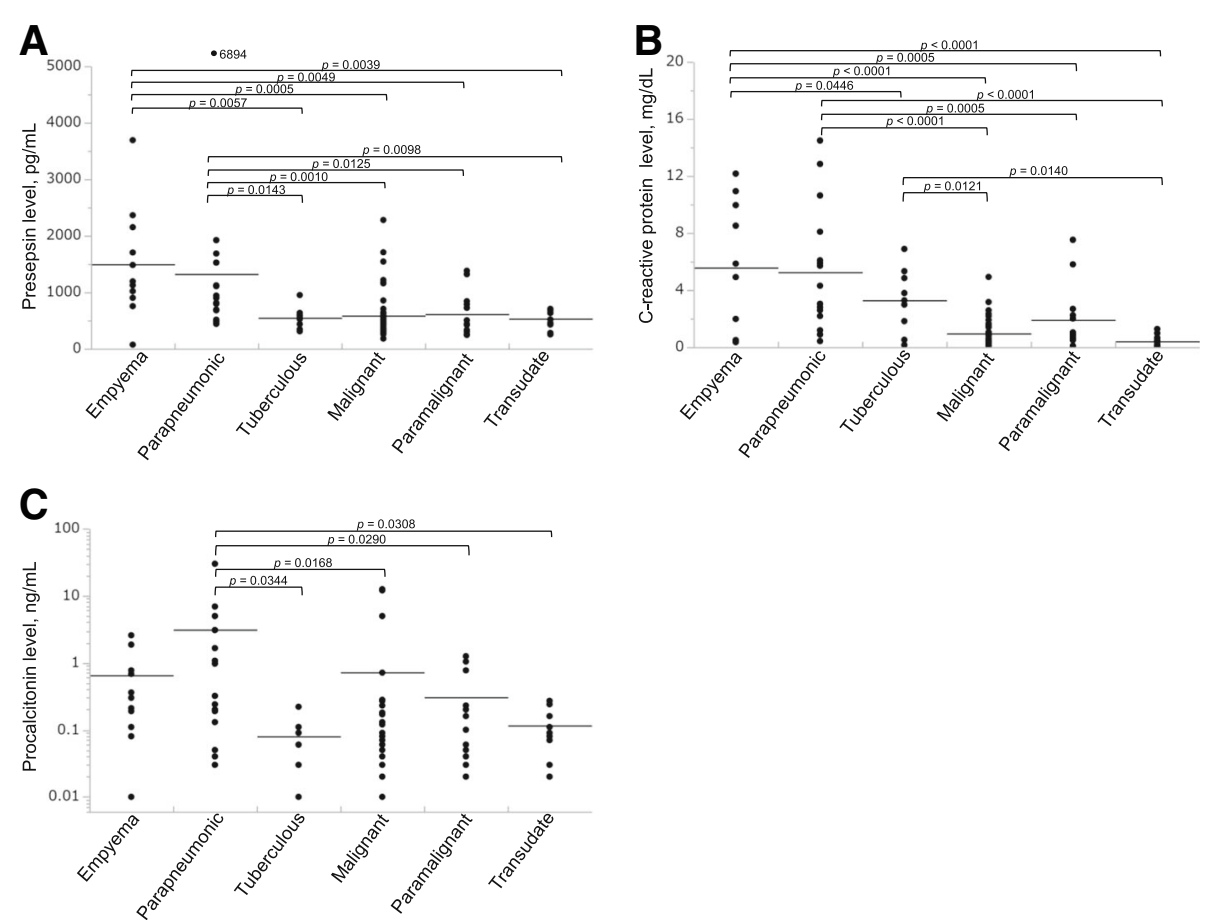

Fig. 1 Pleural fluid presepsin, CRP, and PCT levels. (a-c) Pleural fluid presepsin (a), CRP (b), and PCT (c) levels in the different diagnostic subgroups. Individual values are plotted. Bars represent the means of the values, and $p$-values are shown between only groups with statistically significant differences

effusion and non-infectious pleural effusion, the accuracy rate peaked at $83.3 \%$ for pleural fluid presepsin levels of $>680 \mathrm{pg} / \mathrm{mL}$ and pleural fluid CRP levels of $>2.59$ $\mathrm{mg} / \mathrm{dL}$. Furthermore, when distinguishing between parapneumonic pleural effusion and other types of effusions (excluding empyema in both groups), pleural fluid presepsin levels of $>680 \mathrm{pg} / \mathrm{mL}$ and pleural fluid CRP levels of $>2.18 \mathrm{mg} / \mathrm{dL}$ yielded the highest accuracy rate $(90.1 \%)$. The combination of pleural fluid PCT levels of $<2.57 \mathrm{ng} / \mathrm{mL}$ and pleural fluid CRP levels of $>4.91 \mathrm{mg} / \mathrm{dL}$ yielded the second highest accuracy rate $(87.9 \%)$ in the differentiation of empyema. The combination of PCT and CRP also showed better accuracy than the combination of PCT and presepsin in distinguishing between infectious and non-infectious pleural effusion, parapneumonic pleural effusion, and other types of effusions (excluding empyema in both groups).

\section{Discussion}

We hypothesised that pleural fluid presepsin, CRP, and/or PCT concentration(s) may be of value in the differentiation between several causes of pleural effusions. Thus, this study investigated the diagnostic performance of these three inflammatory markers in the blood and pleural fluid of a well-characterised population of patients with several types of effusions. We found that pleural fluid presepsin levels were significantly higher in cases of empyema and parapneumonic effusion compared with other types of effusions, as well as in cases with infectious pleural effusions compared with non-infectious effusions, although the pleural fluid presepsin level was not elevated in tuberculous effusion cases. Furthermore, pleural fluid presepsin was found to be the most sensitive of the three tested markers for distinguishing between infectious and non-infectious pleural effusions.

Table 3 Diagnostic performance of pleural fluid presepsin based on the ROC analysis $(n=132)$

\begin{tabular}{|c|c|c|c|c|c|c|c|c|c|}
\hline & Optimal cut-off point (pg/mL) & Sensitivity (\%) & Specificity (\%) & $+\mathrm{LR}$ & $-L R$ & PPV (\%) & NPV (\%) & AUC & Accuracy (\%) \\
\hline Emp vs. other & $\geq 754$ & 90.9 & 74.4 & 1.39 & 0.12 & 24.4 & 98.9 & 0.809 & 75.8 \\
\hline Emp and PE vs. other & $\geq 680$ & 85.2 & 74.3 & 3.31 & 0.20 & 46.0 & 95.1 & 0.803 & 76.5 \\
\hline Emp, $P E$, and TB vs. other & $\geq 680$ & 66.7 & 72.9 & 2.46 & 0.46 & 48.0 & 85.4 & 0.728 & 71.2 \\
\hline PE vs. other (excluding Emp) & $\geq 680$ & 81.3 & 74.3 & 3.16 & 0.25 & 32.5 & 96.3 & 0.785 & 75.2 \\
\hline Infectious vs. non-infectious & $\geq 680$ & 68.4 & 74.5 & 2.68 & 0.42 & 52.0 & 85.4 & 0.746 & 72.7 \\
\hline
\end{tabular}

Emp empyema, $P E$ parapneumonic effusions, $T B$ tuberculosis, $+L R$ positive likelihood ratio, $-L R$ negative likelihood ratio $P P V$ positive predictive value, $N P V$ negative predictive value, $A \cup C$ area under the curve 
Table 4 Diagnostic performance of pleural fluid CRP based on the ROC analysis ( $n=132)$

\begin{tabular}{llllllllll}
\hline & Optimal cut-off point (mg/dL) & Sensitivity (\%) & Specificity (\%) & +LR & - LR & PPV (\%) & NPV (\%) & AUC & Accuracy (\%) \\
\hline Emp vs. other & $\geq 4.91$ & 63.6 & 89.3 & 5.93 & 0.41 & 35.0 & 96.4 & 0.757 & 87.1 \\
Emp and PE vs. Other & $\geq 2.59$ & 70.4 & 85.7 & 4.92 & 0.35 & 55.9 & 91.8 & 0.834 & 82.6 \\
Emp, PE and TB vs. Other & $\geq 2.59$ & 69.4 & 90.6 & 7.40 & 0.34 & 73.5 & 88.8 & 0.840 & 84.9 \\
PE vs. other (excluding Emp) & $\geq 2.18$ & 81.3 & 81.0 & 4.27 & 0.23 & 39.4 & 96.6 & 0.859 & 81.0 \\
Infectious vs. non-infectious & $\geq 2.59$ & 65.8 & 90.4 & 6.87 & 0.38 & 73.5 & 86.7 & 0.820 & 83.3 \\
\hline
\end{tabular}

Emp empyema, $P E$ parapneumonic effusions, $T B$ tuberculosis, $+L R$ positive likelihood ratio $-L R$ negative likelihood ratio, $P P V$ positive predictive value, $N P V$ negative predictive value, AUC area under the curve

Our findings on pleural fluid presepsin may support a pathophysiological mechanism of the acute phase response during the development of infection. Kiropoulos et al. [12] investigated the levels of CRP, IL-6, and TNF- $\alpha$ in various types of pleural effusions and reported that pleural fluid CRP was likely to reflect the systemic inflammation induced by the local production of IL- 6 and TNF- $\alpha$ in the pleural cavity. Notably, although IL-6 and TNF- $\alpha$ levels were higher in the pleural fluid than in the serum, we found that pleural fluid CRP levels were significantly lower than serum CRP levels. Similarly, pleural fluid presepsin levels may reflect local production in the pleural cavity as well as the production mechanism of pleural fluid IL- 6 and TNF- $\alpha$.

Although the biological function of presepsin remains unclear, studies in rabbits [13] showed that its release mechanism is likely to be associated with the phagocytosis and cleavage of microorganisms by lysosomes. This finding supports the high levels of pleural fluid presepsin observed in empyema cases in this study. We suggest that locally increased pleural fluid presepsin levels may be attributed to bacterial phagocytosis in pleural effusion. Furthermore, this connection may be one of the reasons that pleural fluid presepsin does not increase in tuberculous effusion compared with empyema or parapneumonic effusion. As confirmed in the present study (Table 1), the proportion of lymphocytes is relatively high in tuberculous pleural effusion [14]. Thus, there are relatively few macrophages and neutrophils in this condition, and the low numbers of these phagocytes may lead to low presepsin production. Presepsin is produced in the pleural space; therefore, measuring presepsin in the pleural fluid may provide a more accurate marker for distinguishing the cause of pleural effusion than measuring presepsin in the blood.

We found that pleural fluid CRP levels were higher in infectious effusions compared with non-infectious effusions. This result supports the value of pleural fluid CRP measurement in diagnosing infectious effusions. Furthermore, it confirms and extends the findings of previous investigations, in which pleural CRP levels were found to be higher in parapneumonic effusions than in other types of exudates. Izhakian et al. [15] reported that pleural CRP levels were higher in parapneumonic effusion than in other effusion types, with a cut-off value of $>1.38 \mathrm{mg} / \mathrm{dL}$. Pleural CRP had a low positive predicted value $(37.6 \%)$ but a very high negative predicted value (96.7\%), which suggests that it could be a powerful tool for excluding parapneumonic effusion as a diagnosis. Several other studies have investigated the relationship between pleural fluid CRP and the cause of pleural effusions, with similar findings $[16,17]$. Although the exact cut-off value varies among studies, pleural fluid CRP levels appear capable of differentiating between infectious effusions and non-infectious effusions. Porcel et al. [4] found that pleural fluid CRP levels of $>10 \mathrm{mg} / \mathrm{dL}$ were associated with complicated parapneumonic effusion and with the need for pleural effusion drainage. Here, we examined whether the marker distribution differed between patients treated with antibiotics alone $(n=5)$ and those treated with drainage or surgical treatment $(n=11)$. No difference in PCT or presepsin levels was found between these groups, but CRP levels trended higher in the group with drainage or surgical treatment.

Table 5 Diagnostic performance of pleural fluid PCT based on the ROC analysis ( $n=132)$

\begin{tabular}{|c|c|c|c|c|c|c|c|c|c|}
\hline & Optimal cut-off point (ng/mL) & Sensitivity (\%) & Specificity (\%) & $+\mathrm{LR}$ & $-L R$ & PPV (\%) & NPV (\%) & AUC & Accuracy (\%) \\
\hline Emp vs. other & $\leq 2.57$ & 100.0 & 5.8 & 1.06 & 0.00 & 8.8 & 100.0 & 0.244 & 13.6 \\
\hline Emp and PE vs. other & $\geq 0.19$ & 70.4 & 83.8 & 4.35 & 0.35 & 52.8 & 91.7 & 0.791 & 81.1 \\
\hline Emp, PE and TB vs. other & $\geq 0.11$ & 66.7 & 75.0 & 2.67 & 0.44 & 50.0 & 85.7 & 0.718 & 72.7 \\
\hline PE vs. other (excluding Emp) & $\geq 0.13$ & 75.0 & 79.0 & 3.58 & 0.32 & 35.3 & 95.4 & 0.783 & 78.5 \\
\hline Infectious vs. non-infectious & $\geq 0.11$ & 63.2 & 74.5 & 2.47 & 0.49 & 50.0 & 83.3 & 0.696 & 71.2 \\
\hline
\end{tabular}

Emp empyema, $P E$ parapneumonic effusion, $T B$ tuberculosis, $+L R$ positive likelihood ratio, $-L R$ negative likelihood ratio, $P P V$ positive predictive value, $N P V$ negative predictive value, $A \cup C$ area under the curve 
Table 6 Diagnostic performance of different marker combinations $(n=132)$

\begin{tabular}{|c|c|c|c|c|c|c|c|}
\hline Cut-off value & Sensitivity (\%) & Specificity (\%) & $+\mathrm{LR}$ & $-L R$ & PPV (\%) & NPV (\%) & Accuracy (\%) \\
\hline \multicolumn{8}{|l|}{ Emp vs. other } \\
\hline Presepsin, 754 pg/mL + CRP, 4.91 mg/dL & 63.6 & 93.4 & 9.63 & 0.39 & 46.7 & 96.6 & 90.9 \\
\hline Presepsin, $754 \mathrm{pg} / \mathrm{mL}+\mathrm{PCT}, \leq 2.57 \mathrm{ng} / \mathrm{mL}$ & 90.9 & 78.5 & 4.23 & 0.12 & 27.8 & 99.0 & 79.6 \\
\hline $\mathrm{CRP}, 4.91 \mathrm{mg} / \mathrm{dL}+\mathrm{PCT}, \leq 2.57 \mathrm{ng} / \mathrm{mL}$ & 63.6 & 90.1 & 6.42 & 0.40 & 36.8 & 96.5 & 87.9 \\
\hline \multicolumn{8}{|l|}{ PE vs. other (excluding Emp) } \\
\hline Presepsin, $680 \mathrm{pg} / \mathrm{mL}+$ CRP, $2.18 \mathrm{mg} / \mathrm{dL}$ & 68.8 & 93.3 & 10.31 & 0.33 & 61.1 & 95.1 & 90.1 \\
\hline Presepsin, $680 \mathrm{pg} / \mathrm{mL}+\mathrm{PCT}, 0.13 \mathrm{ng} / \mathrm{mL}$ & 68.8 & 90.5 & 7.22 & 0.35 & 52.4 & 95.0 & 87.6 \\
\hline CRP, $2.18 \mathrm{mg} / \mathrm{dL}+\mathrm{PCT}, 0.13 \mathrm{ng} / \mathrm{mL}$ & 68.8 & 92.4 & 9.02 & 0.34 & 57.9 & 95.1 & 89.3 \\
\hline \multicolumn{8}{|l|}{ Infectious vs. non-infectious } \\
\hline Presepsin, $680 \mathrm{pg} / \mathrm{mL}+\mathrm{CRP}, 2.59 \mathrm{mg} / \mathrm{dL}$ & 65.8 & 90.4 & 6.87 & 0.38 & 73.5 & 86.7 & 83.3 \\
\hline Presepsin, $680 \mathrm{pg} / \mathrm{mL}+\mathrm{PCT}, 0.11 \mathrm{ng} / \mathrm{mL}$ & 55.3 & 89.4 & 5.19 & 0.50 & 67.7 & 83.2 & 79.6 \\
\hline CRP, $2.59 \mathrm{mg} / \mathrm{dL}+\mathrm{PCT}, 0.11 \mathrm{ng} / \mathrm{mL}$ & 50.0 & 92.6 & 6.71 & 0.54 & 73.1 & 82.1 & 80.3 \\
\hline
\end{tabular}

Emp empyema, $P E$ parapneumonic effusions, $+L R$ positive likelihood ratio, $-L R$ negative likelihood ratio, $P P V$ positive predictive value, $N P V$ negative predictive value

Thus, although the number of cases in the present study was small, its results also suggest that pleural fluid CRP levels vary depending on the treatment.

We examined the relationship between pleural fluid PCT levels and different causes of pleural effusions, which has also been investigated by several previous studies. Among those studies, some reported that pleural fluid PCT measurement is useful in differentiating between parapneumonic and other types of effusions, while others have found that it is not useful for this purpose. Wang et al. [18] reported that PCT levels could differentiate empyema and parapneumonic effusion from non-parapneumonic effusion at a cut-off point of $0.18 \mathrm{ng} / \mathrm{mL}$ and an AUC of 0.776 (sensitivity, 69.7\%; specificity, 72.1\%). Lin et al. [19] also reported that PCT could differentiate parapneumonic effusion from non-parapneumonic effusion at a cut-off point of $0.18 \mathrm{ng} / \mathrm{mL}$ and an AUC of 0.752 (sensitivity, 66.7\%; specificity, 77.4\%). However, Porcel et al. [3] determined that PCT levels in pleural fluid were of little value. Our results show that pleural fluid PCT levels tended to be higher in cases of parapneumonic effusion than in other pleural effusions, supporting its potential use as a tool for diagnosing parapneumonic effusion. Although the small number of cases in this study makes it impossible to make definitive conclusions, pleural fluid PCT levels do not necessarily increase in empyema.

A novel finding of our study is that combinations of pleural fluid markers can distinguish pleural fluid from certain causes with a higher accuracy rate than that of any single pleural fluid marker. In the differentiation of empyema, a combination of pleural fluid presepsin and CRP yielded the highest accuracy rate. In clinical practice, simple cut-off values are easier to remember and apply. Notably, we found that changing the cut-off value of presepsin from $754 \mathrm{pg} / \mathrm{mL}$ to $750 \mathrm{pg} / \mathrm{mL}$ and the CRP cut-off value from $4.91 \mathrm{mg} / \mathrm{dL}$ to $4.9 \mathrm{mg} / \mathrm{dL}$, did not affect the diagnostic performance. Although PCT alone was not useful for the differentiation of empyema, it was found that this marker can be a useful tool when combined with CRP or presepsin. However, for distinguishing between infectious effusion and non-infectious effusion, the accuracy rate of combined markers was not improved over that of pleural fluid CRP alone. Further research on the clinical applicability of various marker combinations is required.

This study should be interpreted in the context of certain limitations. First, the sample size was small, and there was a large variation in case accumulation; although multiple study centres participated, patients were enrolled from both respiratory medicine and outpatient wards. This may have limited the power of its findings. Second, diagnosis based on the physician's judgment may have resulted in the misclassification of some patients, thus compromising the assessment of diagnostic accuracy of the pleural fluid markers. However, as the diagnoses of pleural effusions were performed by board-certified members of the Japanese Respiratory Society at each institution and were made following the same diagnostic criteria, we consider the diagnosis method to have been relatively standardised. Third, dialysis patients and patients with severe renal failure were not included in this study; thus, the findings of this study may not be applicable to patients with severe renal failure. Because presepsin is mainly excreted in the urine, patients with chronic renal failure [20], especially chronic maintenance dialysis patients, tend to have high levels of presepsin. Fourth, the effect of patient background (e.g. underlying disease or the administration of chemotherapy, steroids, or antibiotics) was not analysed in detail; neither was the effect of the type, duration, or dose of antibiotic treatment or the tumour burden [21]. These parameters may have affected the levels of 
acute inflammatory markers. Finally, because the decision to initiate thoracentesis was based on the judgement of the pulmonary physician, a sampling bias may have been present, which could explain the very low number of cases of congestive pleural effusion representative of transudate effusion that were registered during the study period.

\section{Conclusions}

In summary, this study showed that pleural fluid presepsin, CRP, and PCT levels may be of value as additional tools in the assessment of pleural effusions to support the differential diagnosis. High levels of pleural fluid presepsin were found in cases of empyema and parapneumonic effusion; this closely resembles the previously reported pattern of pleural fluid CRP levels. Some combinations of these pleural fluid inflammatory marker may be more likely to be clinically useful compared with these markers in isolation.

\section{Abbreviations}

95\% Cl: 95\% confidence interval; AUC: area under the curve; CRP: C-reactive protein; IL-6: interleukin-6; PCT: procalcitonin; ROC: receiver operator characteristics; SD: standard deviation

\section{Acknowledgements}

We thank Dr. Masahiro Yamaguch and Dr. Akira Tadokoro of the Department of Respiratory Medicine, National Hospital Organization Takamatsu Medical Center; Dr. Takuya Inoue of the Department of Respiratory Medicine, Sakaide City Hospital; and Dr. Hiroshi Miyawaki and Dr. Kenichiro Sakai of the Department of Respiratory Medicine, Kagawa Prefectural Central Hospital for their help in data acquisition. We also thank Katie Oakley, PhD, from Edanz Group for proofreading this manuscript in English.

\section{Funding}

This research did not receive any specific grant from funding agencies in the public, commercial, or not-for-profit sectors.

\section{Availability of data and materials}

The datasets used and/or analysed during the current study are available from the corresponding author upon reasonable request.

\section{Authors' contributions}

NW contributed to the study design, data acquisition, interpretation of the results and statistical analysis, drafting of the manuscript, and critical revisions of the manuscript for its intellectual content. IT, NK1, NK2, and SB participated in the study design, data acquisition, interpretation of the results, and literature review. $\mathrm{HN}, \mathrm{NN}, \mathrm{YU}$, and $\mathrm{YT}$ were involved in data acquisition and interpretation of the results. NK3 supervised manuscript drafting. All authors have read and approved the final version of the manuscript.

\section{Ethics approval and consent to participate}

Ethical approval has been obtained from the institutional review board of Kagawa University Hospital (27-113). Written informed consent was obtained from all patients prior to participation.

\section{Consent for publication}

Not applicable.

\section{Competing interests}

The authors declare that they have no competing interests.

\section{Publisher's Note}

Springer Nature remains neutral with regard to jurisdictional claims in published maps and institutional affiliations.

\section{Author details}

'Department of Internal Medicine, Hematology, Rheumatology and Respiratory Medicine, Faculty of Medicine, Kagawa University, 1750-1 Ikenobe, Miki-cho, Kita-gun, Kagawa 761-0793, Japan. ²Department of Respiratory Medicine, Sakaide City Hospital, 3-1-2, Kotobuki-cho, Sakaide, Kagawa 762-8550, Japan. ${ }^{3}$ Department of Respiratory Medicine, Sanuki Municipal Hospital, 387-1, Ishidahigashi-kou, Sangawa-cho, Sanuki, Kagawa 769-2393, Japan. ${ }^{4}$ Department of Respiratory Medicine, Kagawa Prefectural Central Hospital, 1-2-1, Asahimachi, Takamatsu, Kagawa 760-8557, Japan. ${ }^{5}$ Department of Respiratory Medicine, National Hospital Organization Takamatsu Medical Center, 8, Shindencho-otsu, Takamatsu, Kagawa 761-0193, Japan.

Received: 5 February 2018 Accepted: 13 November 2018

Published online: 23 November 2018

\section{References}

1. Light RW, Macgregor MI, Luchsinger PC, Ball WC Jr. Pleural effusions: the diagnostic separation of transudates and exudates. Ann Intern Med. 1972; 77(4):507-13.

2. Maskell NA, Davies CW, Nunn AJ, Hedley EL, Gleeson FV, Miller R, Gabe R, Rees GL, Peto TE, Woodhead MA, et al. U.K. controlled trial of intrapleural streptokinase for pleural infection. N Engl J Med. 2005;352(9):865-74.

3. Porcel JM, Vives M, Cao G, Bielsa S, Ruiz-Gonzalez A, Martinez-Iribarren A, Esquerda A. Biomarkers of infection for the differential diagnosis of pleural effusions. Eur Respir J. 2009;34(6):1383-9.

4. Porcel JM, Bielsa S, Esquerda A, Ruiz-Gonzalez A, Falguera M. Pleural fluid Creactive protein contributes to the diagnosis and assessment of severity of parapneumonic effusions. Eur J Intern Med. 2012;23(5):447-50.

5. Daniil ZD, Zintzaras E, Kiropoulos T, Papaioannou Al, Koutsokera A, Kastanis A, Gourgoulianis KI. Discrimination of exudative pleural effusions based on multiple biological parameters. Eur Respir J. 2007;30(5):957-64.

6. Yaegashi Y, Shirakawa K, Sato N, Suzuki Y, Kojika M, Imai S, Takahashi G, Miyata M, Furusako S, Endo S. Evaluation of a newly identified soluble CD14 subtype as a marker for sepsis. J Infect Chemother. 2005;11(5):234-8.

7. Endo S, Suzuki Y, Takahashi G, Shozushima T, Ishikura H, Murai A, Nishida T, Irie $Y$, Miura $M$, Iguchi $H$, et al. Presepsin as a powerful monitoring tool for the prognosis and treatment of sepsis: a multicenter prospective study. J Infect Chemother. 2014;20(1):30-4.

8. Mussap M, Noto A, Fravega M, Fanos V. Soluble CD14 subtype presepsin (sCD14-ST) and lipopolysaccharide binding protein (LBP) in neonatal sepsis: new clinical and analytical perspectives for two old biomarkers. J Matern Fetal Neonatal Med. 2011;24(Suppl 2):12-4.

9. Shozushima T, Takahashi G, Matsumoto N, Kojika M, Okamura Y, Endo S. Usefulness of presepsin (sCD14-ST) measurements as a marker for the diagnosis and severity of sepsis that satisfied diagnostic criteria of systemic inflammatory response syndrome. J Infect Chemother. 2011;17(6):764-9.

10. Endo S, Suzuki Y, Takahashi G, Shozushima T, Ishikura H, Murai A, Nishida T, Irie $Y$, Miura M, Iguchi $\mathrm{H}$, et al. Usefulness of presepsin in the diagnosis of sepsis in a multicenter prospective study. J Infect Chemother. 2012;18(6):891-7.

11. Klouche K, Cristol JP, Devin J, Gilles V, Kuster N, Larcher R, Amigues L, Corne P, Jonquet O, Dupuy AM. Diagnostic and prognostic value of soluble CD14 subtype (Presepsin) for sepsis and community-acquired pneumonia in ICU patients. Ann Intensive Care. 2016;6(1):59.

12. Kiropoulos TS, Kostikas K, Oikonomidi S, Tsilioni I, Nikoulis D, Germenis A, Gourgoulianis Kl. Acute phase markers for the differentiation of infectious and malignant pleural effusions. Respir Med. 2007;101(5):910-8.

13. Shirakawa K, Naitou K, Hirose J, Nakamura M, Takeuchi T, Hosaka Y, Furusako S. The new sepsis marker, SCD14-ST, induction mechanism in the rabbit sepsis models. Crit Care. 2010;14(Supple 2).

14. Epstein DM, Kline LR, Albelda SM, Miller WT. Tuberculous Pleural Effusions. Chest. 1987;91(1):106-9.

15. Izhakian S, Wasser WG, Fox BD, Vainshelboim B, Kramer MR. The diagnostic value of the pleural fluid C-reactive protein in Parapneumonic effusions. Dis Markers. 2016;2016:7539780.

16. Skouras V, Boultadakis E, Nikoulis D, Polychronopoulos V, Daniil Z, Kalomenidis I, Gourgoulianis Kl. Prognostic value of C-reactive protein in parapneumonic effusions. Respirology. 2012;17(2):308-14.

17. Yilmaz Turay U, Yildirim Z, Turkoz Y, Biber C, Erdogan Y, Keyf Al, Ugurman F, Ayaz A, Ergun P, Harputluoglu M. Use of pleural fluid C-reactive protein in diagnosis of pleural effusions. Respir Med. 2000;94(5):432-5. 
18. Wang CY, Hsiao YC, Jerng JS, Ho CC, Lai CC, Yu CJ, Hsueh PR, Yang PC. Diagnostic value of procalcitonin in pleural effusions. Eur J Clin Microbiol Infect Dis. 2011;30(3):313-8.

19. Lin MC, Chen YC, Wu JT, Ko YC, Wang CC. Diagnostic and prognostic values of pleural fluid procalcitonin in parapneumonic pleural effusions. Chest. 2009:136(1):205-11.

20. Kotera A, Sagishima K, Tashiro T, Niimori D, Kamohara H, Kinoshita Y. A validation of presepsin levels in kidney dysfunction patients: four case reports. J Intensive Care. 2014;2(1):63.

21. Heikkila K, Ebrahim S, Lawlor DA. A systematic review of the association between circulating concentrations of $C$ reactive protein and cancer. J Epidemiol Community Health. 2007;61(9):824-33.

Ready to submit your research? Choose BMC and benefit from:

- fast, convenient online submission

- thorough peer review by experienced researchers in your field

- rapid publication on acceptance

- support for research data, including large and complex data types

- gold Open Access which fosters wider collaboration and increased citations

- maximum visibility for your research: over $100 \mathrm{M}$ website views per year

At $\mathrm{BMC}$, research is always in progress.

Learn more biomedcentral.com/submissions 